in vivo $35: 883-888(2021)$

doi:10.21873/invivo.12328

\title{
Vignacyanidin Polyphenols Isolated from Vigna Angularis Bean Promote Osteoblast Differentiation
}

\author{
THIRA ROJASAWASTHIEN ${ }^{1,2}$, TOMOHIKO SHIRAKAWA ${ }^{1}$, AYAKO WASHIO $^{3}$, \\ TOSHIYUKI TSUJISAWA ${ }^{4}$, TAKUMA MATSUBARA ${ }^{1}$, ASAKO INOUE ${ }^{1}$, \\ UMEO TAKAHAMA $^{5}$, KEISUKE NAKASHIMA ${ }^{2}$ and SHOICHIRO KOKABU ${ }^{1}$ \\ ${ }^{1}$ Division of Molecular Signaling and Biochemistry, \\ Department of Health Improvement, Kyushu Dental University, Kitakyushu, Japan; \\ ${ }^{2}$ Division of Periodontology, Department of Oral Function, Kyushu Dental University, Kitakyushu, Japan; \\ ${ }^{3}$ Division of Endodontics and Restorative Dentistry, \\ Department of Oral Functions, Kyushu Dental University, Kitakyushu, Japan; \\ ${ }^{4}$ School of Oral Health Sciences, Kyushu Dental University, Kitakyushu, Japan; \\ ${ }^{5}$ Division of Community Oral Health Development, Kyushu Dental University, Kitakyushu, Japan
}

\begin{abstract}
Background/Aim: An effective bone regenerative method needs to be established for the dental field. To identify a novel osteogenic factor for bone regeneration, we examined the effect of vignacyanidin (VIG) on osteoblastogenesis. Materials and Methods: W20-17 cells, MC3T3-E1 cells, and primary cultured murine calvarial osteoblasts were used. Osteoblast differentiation was stimulated by $\beta$-glycerophosphate, ascorbic acid, or bone morphogenetic protein (BMP)-4. Adipogenesis was induced using dexamethasone, 3-isobutyl-1-methylxanthine, insulin, and rosiglitazone. Differentiation or proliferation markers were determined using western blotting and/or the quantitative reverse transcription polymerase chain reaction. Adipogenic cells were visualized by Oil Red $O$ staining. Results: VIG treatment increased the expression of osteoblastic markers and alkaline phosphatase activity of osteoblast-lineage cells in a concentration-dependent manner. However, adipogenesis and cell proliferation were not affected by VIG. Conclusion: VIG treatment promoted osteoblast differentiation in osteoblast-lineage cells.
\end{abstract}

Alveolar bone defects arise mainly from periodontal diseases such as periodontitis. Patients who lose their teeth due to infection or inflammation may experience alveolar bone

This article is freely accessible online.

Correspondence to: Shoichiro Kokabu, DDS, Ph.D., 2-6-1 Kitakyushu, Manazuru, Fukuoka 803-8580, Japan. Tel: +81 932851131, Fax: +81 932856000, e-mail: r14kokabu@fa.kyu-dent.ac.jp

Key Words: Vignacyanidin, polyphenol, flavonoid, Adzuki bean. resorption. In addition to being uncomfortable, this bone loss can cause dental disfigurement and complicate the adaptation of dental implants and other prosthetic appliances. Although dental implants are regarded as an effective treatment for recovering the occlusal function of missing teeth, many patients do not have adequate bone volume for building dental implants (1). Therefore, an effective method to increase bone formation by osteoblasts is required.

Bone is continuously remodeled by the processes of bone resorption by osteoclasts and bone formation by osteoblasts. Osteoclasts originate from hematopoietic monocyte/ macrophage lineage cells that are present in the bone marrow and blood (2). In contrast, osteoblast-lineage cells, such as osteoblasts and osteocytes, are derived from bone marrow mesenchymal stem cells (BMMSCs) (3). BMMSCs are multipotent stem cells that can differentiate not only into osteoblast-lineage cells, but also into other cell types, including adipocytes (4).

Bioactive molecules, such as growth factors, are considered useful for bone regeneration. These molecules include insulin-like growth factor, fibroblast growth factor 2, platelet-derived growth factor, bone morphogenetic protein (BMP)s, and transforming growth factor beta (5). They stimulate the proliferation and differentiation of osteoprogenitor cells $(6,7)$. However, the clinical application of bioactive molecules is limited because of concerns regarding their safety and cost-effectiveness (8). Thus, new supportive drugs that induce bone regenerations are required.

Polyphenols are chemical compounds with multiple phenol units $\left(\mathrm{C}_{6} \mathrm{H}_{6} \mathrm{O}\right)$. They are synthesized naturally by plants. Humans benefit from dietary intake of polyphenols, including improvements in bone health $(9,10)$. Polyphenols affect osteoblasts by regulating different signaling pathways, 
A

Non-treatment

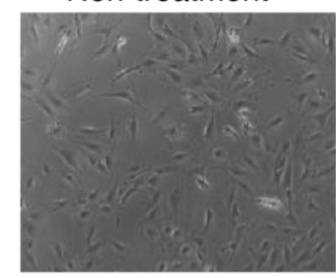

B

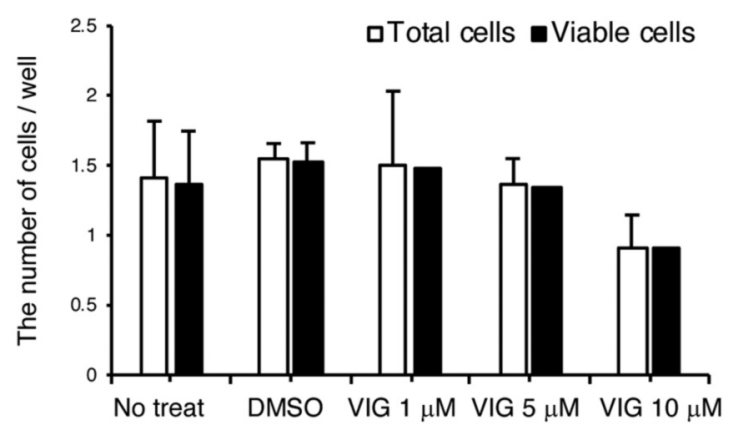

VIG $1 \mu \mathrm{M}$
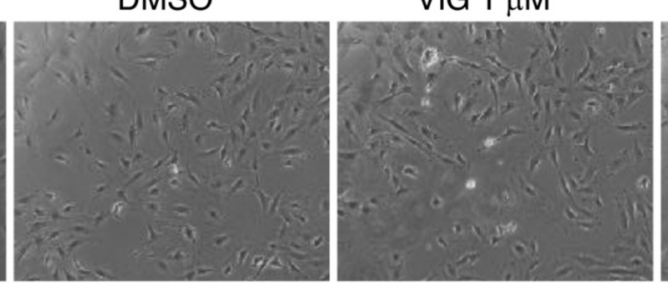

VIG $5 \mu \mathrm{M}$

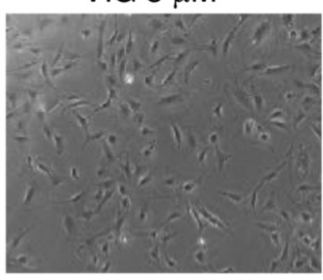

C

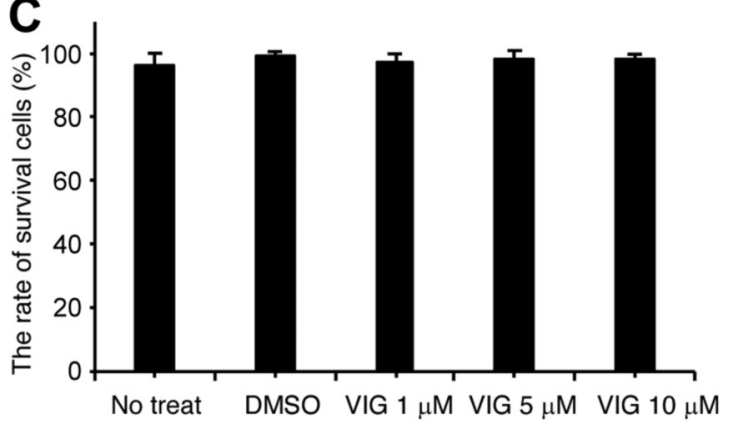

Figure 1. The effect of vignacyanidin (VIG) on the viability of MC3T3-E1 cells. (A-C) MC3T3-E1 cells were treated with 0.5 ml dimethyl sulfoxide (DMSO) or $0.5 \mathrm{ml}$ VIG diluted in DMSO (final concentrations: 1, 5, or $10 \mu \mathrm{M}$ ). After 48 h, the morphology of cells was observed using phasecontrast microscopy (A). After detaching the cells with a brief exposure to trypsin/EDTA, the number of cells was counted. In addition, the number of viable cells that excluded Trypan Blue dye was determined (B). Cell survival was calculated by dividing the number of viable cells by the total number of cells $(C)$. Original magnification, $4 \times(A)$. Data are presented as mean $\pm S D(n=4)$.

such as those involving canonical Wnts $(11,12)$, insulin-like growth factor (13), BMPs (14), runt-related transcription factor 2 (Runx2) (15), and Osterix (Osx) (16). Moreover, because of their structural similarity to mammalian estrogens, some polyphenols, such as isoflavones, can bind to estrogen receptors and act as hormone analogs (17).

We have previously isolated a purplish compound belonging to the catechin group from adzuki beans, and named it vignacyanidin (VIG) $(18,19)$. Recently, its chemical structure has been elucidated (20). However, the effect of VIG on bone metabolism remains unknown. Here, we demonstrated that VIG stimulates osteoblast proliferation and differentiation in vitro.

\section{Materials and Methods}

Extraction and purification of VIG from adzuki beans. The methods used to extract and purify VIG from adzuki beans (cultivar "Erimoshozu") have been described previously $(18,19)$. Briefly, dried adzuki beans were soaked in water and left overnight at room temperature. After removing the water, the pigments in the soaked beans were extracted with $1 \% \mathrm{HCl}$ in methanol. The extract was concentrated using a rotary evaporator with ethyl acetate. Purplish pigments in the ethyl acetate extract were purified using Sephadex LH-20 and preparative HPLC.

Cell culture and treatments. The mouse calvarial osteoblast cell line MC3T3-E1 was obtained from Riken BioResource Center (Tsukuba,
Japan). MC3T3-E1 cells were cultured and maintained in $\alpha$-minimal essential medium (Fujifilm Wako Pure Chemical Corporation, Osaka, Japan) supplemented with 10\% fetal bovine serum (Nichirei BIosciences Inc., Tokyo, Japan), and $100 \mathrm{U} / \mathrm{ml}$ penicillinstreptomycin (Fujifilm Wako Pure Chemical Corporation). W20-17 cells were obtained from American type culture collection (Manassas, VA, USA), cultured, and maintained as described previously $(21,22)$. Primary cultured osteoblasts were prepared by sequential digestion of newborn mouse calvarial bones by collagenase and dispase, as described previously (23). The animal experiments were approved by the animal experiment committee of Kyushu Dental University (approved number \#19-011). Osteoblast differentiation of MC3T3-E1 cells or primary cultured calvarial osteoblasts was stimulated by culturing the cells in an osteogenic medium containing $50 \mu \mathrm{g} / \mathrm{ml}$ ascorbic acid (Fujifilm Wako Pure Chemical Corporation) and $10 \mathrm{mM} \beta$-glycerophosphate (SigmaAldrich, St. Louis, MO, USA) for 7 days. W20-17 cells were treated with $0,1,5$, or $10 \mu \mathrm{M}$ VIG along with $20 \mathrm{ng} / \mathrm{ml}$ recombinant human BMP-4 (R \& D systems, Minneapolis, MN, USA) for 3 days. For the adipogenesis assay, W20-17 cells were treated with $0,1,5$, or $10 \mu \mathrm{M}$ VIG along with $10 \mu \mathrm{M}$ dexamethasone (Fujifilm Wako Pure Chemical Corporation), $0.5 \mathrm{mM}$ 3-isobutyl-1-methylxanthine (Fujifilm Wako Pure Chemical Corporation), $10 \mu \mathrm{g} / \mathrm{ml}$ insulin (Fujifilm Wako Pure Chemical Corporation), and $10 \mu \mathrm{M}$ rosiglitazone (Fujifilm Wako Pure Chemical Corporation).

Cell viability assay. MC3T3-E1 cells were plated into 24-well culture plates at $1.0 \times 10^{4}$ cells per well. Five hours after plating, the cells were treated with a-minimal essential medium supplemented with $5 \%$ fetal bovine serum and $0.5 \mathrm{ml}$ dimethyl 

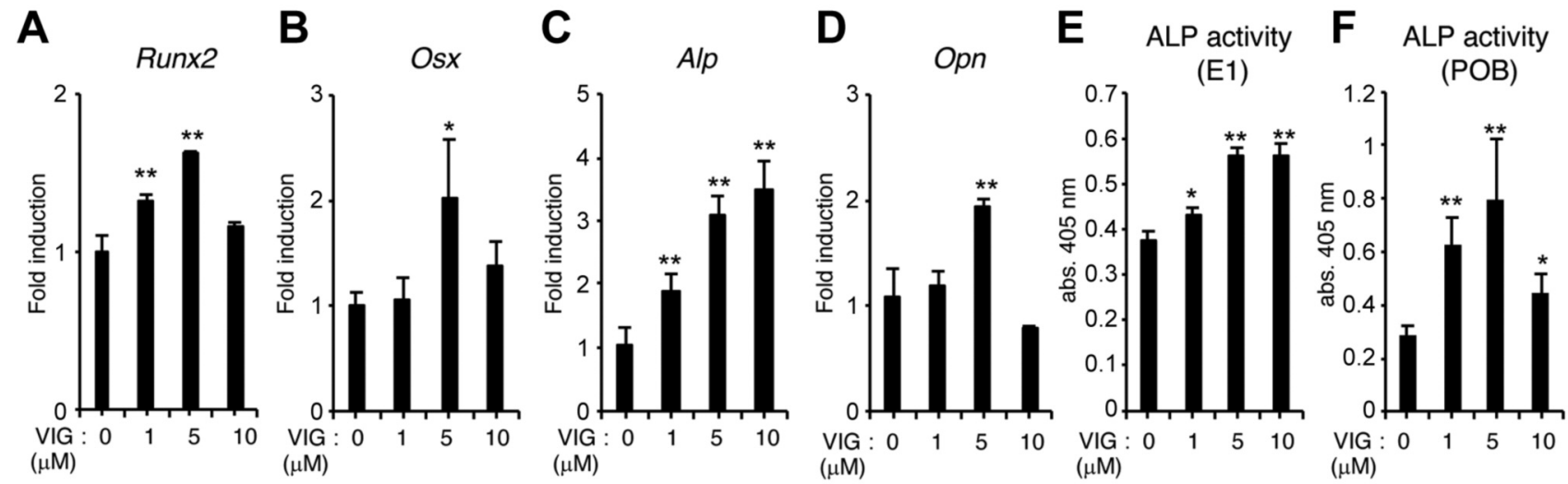

Figure 2. Vignacyanidin (VIG) stimulates osteoblast differentiation of osteoblast-lineage cells. (A-E) MC3T3-E1 cells were cultured in osteogenic medium (growth medium supplemented with $50 \mu \mathrm{g} / \mathrm{ml}$ ascorbic acid, and $10 \mathrm{mM} \beta$-glycerophosphate) with 0 , 1,5 , or $10 \mu \mathrm{M}$ VIG for 7 days. The mRNA levels of Runt-related transcription factor 2 (Runx2) (A), Osterix (Osx) (B), Alkaline phosphatase (Alp) (C), and Osteopontin (Opn) (D) were determined by quantitative real-time polymerase chain reaction. ALP activity was also assessed (E). Primary cultured calvarial osteoblasts were treated with 0, 1, 5, or $10 \mu \mathrm{M}$ VIG along with $10 \mathrm{mM} \beta$-glycerophosphate and $50 \mu \mathrm{g} / \mathrm{ml}$ ascorbic acid for 7 days, and ALP activity was assessed (F). Data are presented as mean $\pm S D(n=4)$. **p<0.01, *p<0.05, versus control treatment.

sulfoxide (Fujifilm Wako Pure Chemical Corporation) or $0.5 \mathrm{ml}$ of VIG solution diluted in this solvent (final VIG concentrations: 1, 5 , or $10 \mu \mathrm{M}$ ). Two days later, the attached cells were rinsed with phosphate-buffered saline (PBS) and detached with a brief exposure to trypsin/ethylenediaminetetraacetic acid (Fujifilm Wako Pure Chemical Corporation). A $10 \mathrm{ml}$ aliquot of the cell suspension was mixed with an equal volume of Trypan Blue (Fujifilm Wako Pure Chemical Corporation) and placed in a TC10 automated cell counter (BIO-RAD Laboratories, Hercules, CA, USA). Viable cells that excluded the Trypan Blue dye were counted. In addition, the morphology of the cells was observed using phase-contrast microscopy (24).

RNA isolation and the quantitative real-time polymerase chain reaction. Total RNA was isolated from the cells using a FastGene ${ }^{\mathrm{TM}}$ RNA Basic Kit (Nippon Genetics, Tokyo, Japan) and reversetranscribed into cDNA using the High-Capacity cDNA Reverse Transcription Kit (Applied Biosystems, Waltham, MA, USA). The SYBR green-based quantitative polymerase chain reaction was performed using PowerUp SYBR (ThermoFisher Scientific, Waltham, MA, USA) and the QuantStudio 3 Real-Time PCR System (ThermoFisher Scientific). cDNA was detected and quantified using specific primers against genes encoding murine Runt-related transcription factor 2 (Runx2) (primer sequences: forward, TTCAACGATCTGAGATTTGTGGG; reverse, GGATGAGGAATGCGCCCTA), murine Osterix (Osx) (primer sequences: forward, AGAGATCTGAGCTGGGTAGAGG; reverse, AAGAGAGCCTGGCAAGAGG), murine Alkaline phosphatase (Alp) (primer sequences: forward, CGGGACTGGTACTCGGATAA; reverse, ATTCCACGTCGGTTCTGTTC), murine Osteopontin $(\mathrm{Opn})$ (primer sequences: forward, TTTCGCAGACCTHACATCC; reverse, GGCTGTCCCAATCAGAAGG), murine Osteocalcin (Oc) (primer sequences: forward, AGACTCCGGCGCTACCTT; reverse, CTCGTCACAAGCAGGGTTAAG), murine Cyclin A2 (primer sequences: forward, CTTGGCTGCACCAACAGTAA; reverse, CAAACTCAGTTCTCCCAAAACA), murine Cyclin D1 (primer sequences: forward, TTTCTTTCCAGAGTCATCAAGTGT; reverse, TGACTCCAGAAGGGCTTCAA), murine Cyclin E1 (primer sequences: forward, TTTCTGCAGCGTCATCCTC; reverse, TGGAGCTTATAGACTTCGCACA), or murine $\beta$-actin (primer sequences: forward, AAGGCCAACCGTGAAAAGAT; reverse, GTGGTACGACCAGAGGCATAC). Expression levels were normalized to $\beta$-actin using the $2^{-\Delta \Delta \mathrm{Ct}}$ method (25).

Alkaline phosphatase activity (ALP) activity. Cells were treated with an ethanol/acetone (50:50) mixture and incubated with a substrate solution composed of $0.1 \mathrm{M}$ diethanolamine, $1 \mathrm{mM} \mathrm{MgCl} 2$, and 1 $\mathrm{mg} / \mathrm{ml}$ p-nitrophenyl phosphate. The reaction was stopped by adding $3 \mathrm{M} \mathrm{NaOH}$. Absorbance values were measured at $405 \mathrm{~nm}$ (23).

Oil Red $O$ staining. On day 7, adipogenic cultures of W20-17 cells were washed twice with PBS and fixed in $4 \%$ paraformaldehyde buffer. The cells were then stained with Oil Red O (Sigma-Aldrich) for $10 \mathrm{~min}$ at room temperature (26).

Proliferation assay. MC3T3-E1 cells were cultured in the presence of various concentrations of VIG for 1, 2, and 3 days. The proliferation of MC3T3-E1 cells was assessed using Cell Counting Kit-8 (Dojindo, Kumamoto, Japan), according to the manufacturer's protocol (27).

Western blot analyses. An anti-Cyclin D1 mouse monoclonal antibody (72-13G, Santa Cruz, Santa Cruz, CA, USA), anti-Cyclin A2 rabbit polyclonal antibody (GST103042, Gentex, Irvine, CA, USA), and anti$\beta$-actin mouse monoclonal antibody (Sigma Aldrich Chemicals) were used for western blotting analyses. Target proteins were visualized using anti-rabbit or anti-mouse $\operatorname{IgG}$ antibodies conjugated with horseradish peroxidase (Cell signaling, Beverly, MA, USA) and ImmunoStar LD (Fujifilm Wako Pure Chemical Corporation).

Statistical analyses. Comparisons were made using an unpaired analysis of variance (ANOVA) with the Tukey-Kramer post-hoc or Wilcoxon signed-rank tests. Data are shown as mean \pm standard deviations. 

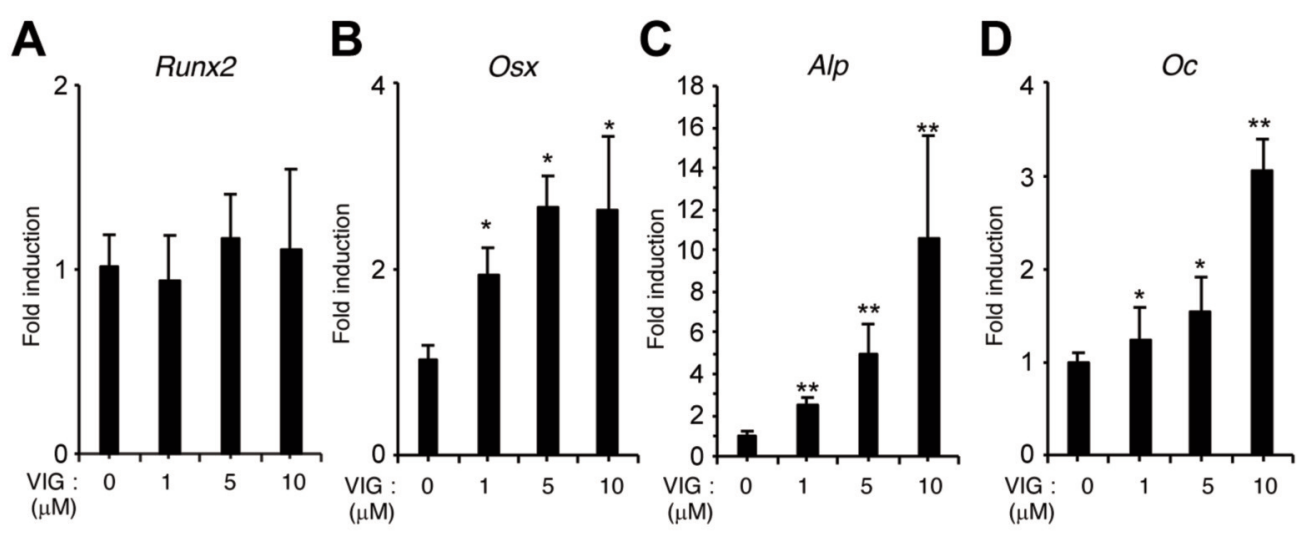

$\mathbf{E}$
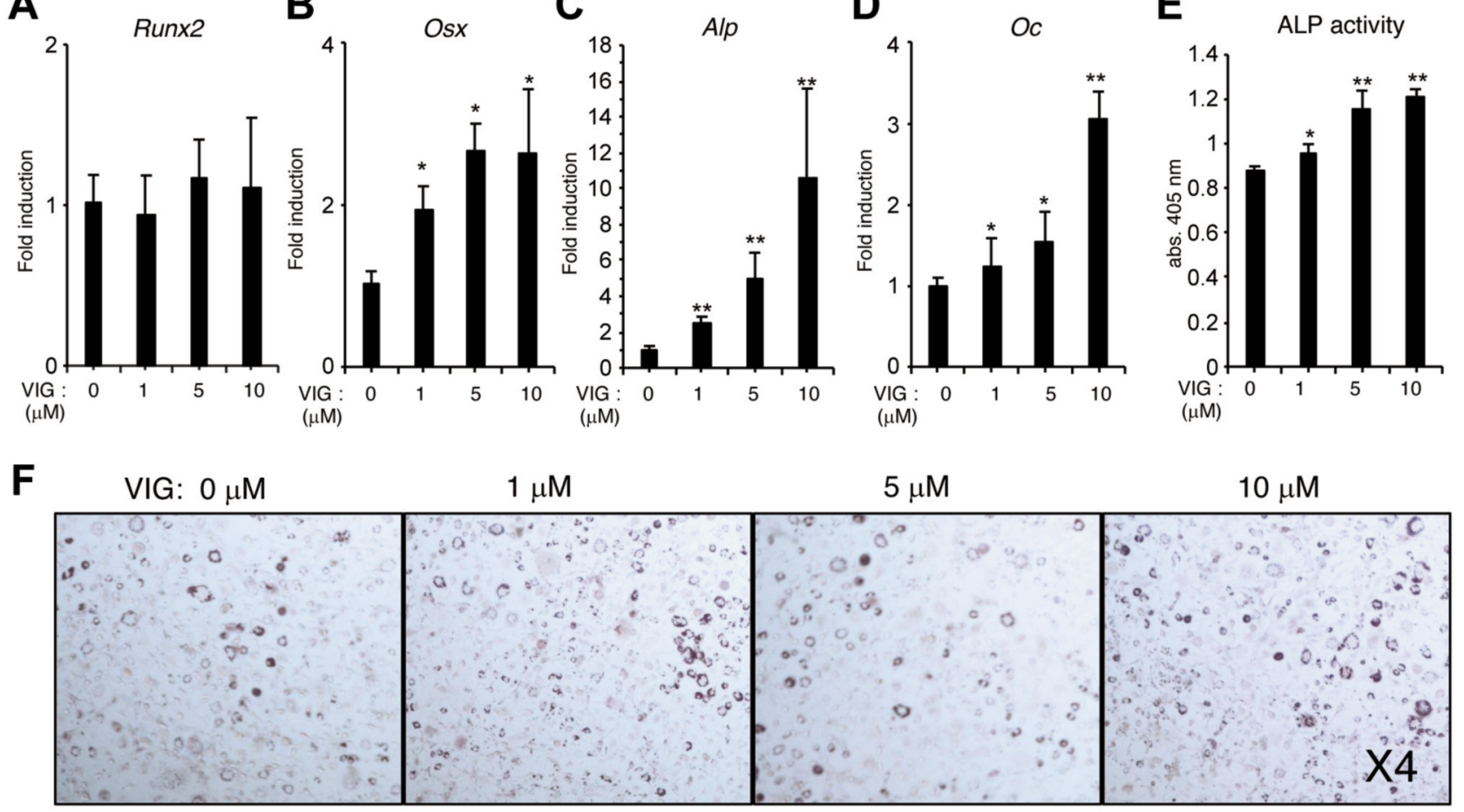

Figure 3. Vignacyanidin (VIG) stimulates osteoblast differentiation but does not affect adipogenesis of bone marrow mesenchymal stem cells. (AE) W20-17 cells were treated with 0, 1, 5, or $10 \mu \mathrm{M}$ VIG along with $20 \mathrm{ng} / \mathrm{ml}$ of recombinant human bone morphogenic protein-4 for 3 days. The mRNA levels of runt-related transcription factor 2 (Runx2) (A), Osterix (Osx) (B), Alkaline phosphatase (Alp) (C), and Osteocalcin (Oc) (D) were determined by quantitative real-time polymerase chain reaction. ALP activity was also assessed $(E)$. $(F) W 20-17$ cells were treated with $0,1,5$, or $10 \mu \mathrm{M}$ VIG along with $0.5 \mathrm{mM}$ of 3-isobutyl-1-methylxanthine, $10 \mu \mathrm{M}$ dexamethasone, $10 \mu \mathrm{g} / \mathrm{ml}$ insulin, and $10 \mu \mathrm{M}$ rosiglitazone. Adipocytes were stained with Oil Red $O$ on day 7. Original magnification, $4 \times$. Data are presented as mean $\pm S D(n=4)$.**p<0.01, *p<0.05, versus control treatment.

\section{Results}

VIG stimulates osteoblast differentiation. First, we determined the appropriate concentration of VIG using the murine calvarial osteoblast cell line, MC3T3-E1. The concentration range of VIG was referenced from a previous study (28). In the current study, VIG did not affect cell morphology (Figure 1A), the total number of cells (Figure 1B), or cell survival (Figure 1C) at concentrations at or under $10 \mu \mathrm{M}$. Therefore, we selected $10 \mu \mathrm{M}$ VIG for further experiments.

We examined whether VIG induced osteoblast differentiation by assessing expression the mRNA levels of the osteoblast markers, Runt-related transcription factor 2 (Runx2), Osterix (Osx), alkaline phosphatase (Alp), and osteopontin $(O p n)$ in MC3T3-E1 cells. VIG increased the levels of these markers in a concentration-dependent manner (Figure 2A-D). VIG also stimulated ALP activity not only in MC3T3-E1 cells (Figure 2E), but also in primary cultured calvarial osteoblasts (Figure $2 \mathrm{~F}$ ).

VIG enhances osteoblast differentiation induced by BMP-4 but does not affect adipogenesis of BMMSCs. We examined the effect of VIG on osteoblast differentiation using W20-17 murine bone marrow stromal cells. VIG enhanced the mRNA levels of Osx, Alp, and Osteocalcin $(O c)$ (Figure 3A$\mathrm{D})$, as well as ALP activity (Figure 3E), induced by BMP-4. However, VIG treatment did not affect the adipogenesis of W20-17 cells (Figure 3F).

VIG does not affect osteoblast proliferation. We examined the effect of VIG on the proliferation of MC3T3-E1 cells. VIG did not affect the number of cells (Figure 4A). Further, VIG did not affect the mRNA or protein levels of the cell cycle-related proteins Cyclin D1, Cyclin A2, and Cyclin E1 (Figure 4B-E).

\section{Discussion}

In this study, we report that VIG promotes osteoblast differentiation of osteoblast-lineage cells without affecting proliferation or adipogenesis. Although osteo-inductive BMPs have been regarded as some of the most important molecules for bone regeneration, their clinical application has not been widespread (22). One reason is a lack of clinical efficacy; for example, primates, including humans, 

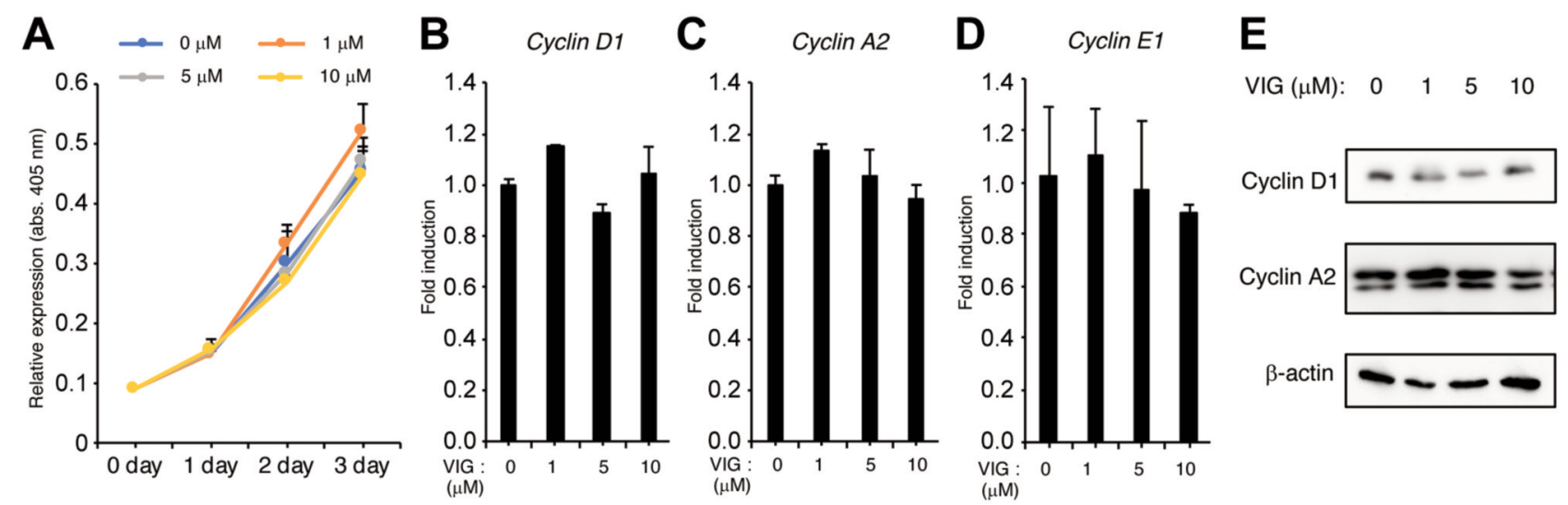

Figure 4. Vignacyanidin (VIG) does not affect the proliferation of osteoblasts. (A-E) MC3T3-E1 cells were cultured in the presence of 0, 1, 5, or 10 $\mu M$ VIG for 1, 2, and 3 days. Cell proliferation was assessed using Cell Counting Kit-8 (A). The mRNA levels of Cyclin D1 (B), Cyclin A2 (C), and $C y c l i n E 1(D)$ were determined by quantitative real-time polymerase chain reaction. $(E)$ Western blotting results depict the protein levels of Cyclin $D 1$, Cyclin A2, and $\beta$-actin. Images are representative of multiple independent experiments. Data are presented as mean $\pm S D(n=4)$.

exhibit a poor response to BMPs and require high doses to achieve the same osteo-inductive effects shown in rodents (29). Thus, the development of molecules that enhance the effect of BMPs is required to reduce the quantity needed for clinically relevant results. In our study, VIG synergistically enhanced BMP-4-induced ALP activity and osteoblast differentiation (Figure 3), suggesting that VIG may be used in combination with BMP to facilitate bone regeneration.

The relationship between osteoblastogenesis and adipogenesis appears to be reciprocal. An increase in adipogenesis relative to osteoblastogenesis of BMMSCs is associated with decreased bone quality and quantity (30). Therefore, it is not sufficient to increase the number of osteoblast progenitor cells (BMMSCs) to stimulate osteoblastogenesis. Rather, it is also important to prevent adipogenesis of BMMSCs. In our study, VIG did not affect the adipogenesis of BMMSCs, although it firmly enhanced osteoblastogenesis (Figure 3). Further research is required to elucidate the mechanism by which VIG regulates cell fate switching in BMMSCs.

In conclusion, VIG induces differentiation of osteoblastlineage cells. VIG can be taken orally; hence, treatment with VIG provides a novel bone regenerative therapy, especially as a supportive drug for BMPs.

\section{Conflicts of Interest}

The Authors declare that they have no conflicts of interest in relation to this study.

\section{Authors' Contributions}

T. R., T. S., A. W., U. T., and S. K. performed the experiments. T. R., T. M., A. W., T. T., K. M., A. I., U. T., K. N., and S. K. reviewed the intermediate draft. S. K. designed the study. S. K. performed the literature review, prepared the initial and final versions of the article, and submitted the document.

\section{Acknowledgements}

This study was supported by The Tojuro Iijima Foundation for Food Science and Technology (to S. K.) and Japan Pulse Foundation (to S. K.).

\section{References}

1 Jimi E, Hirata S, Osawa K, Terashita M, Kitamura C and Fukushima $\mathrm{H}$ : The current and future therapies of bone regeneration to repair bone defects. Int J Dent 2012: 148261, 2012. PMID: 22505894. DOI: 10.1155/2012/148261

2 Teitelbaum SL: Bone resorption by osteoclasts. Science 289(5484): 1504-1508, 2000. PMID: 10968780. DOI: 10.1126/science.289.5484.1504

3 Owen M: Marrow stromal stem cells. J Cell Sci Suppl 10(63-76), 1988. PMID: 3077943. DOI: 10.1242/jcs.1988.supplement_10.5

4 Chamberlain G, Fox J, Ashton B and Middleton J: Concise review: Mesenchymal stem cells: Their phenotype, differentiation capacity, immunological features, and potential for homing. Stem Cells 25(11): 2739-2749, 2007. PMID: 17656645. DOI: 10.1634/stemcells.2007-0197

5 Padial-Molina M, O'Valle F, Lanis A, Mesa F, Dohan Ehrenfest DM, Wang HL and Galindo-Moreno P: Clinical application of mesenchymal stem cells and novel supportive therapies for oral bone regeneration. Biomed Res Int 2015: 341327, 2015. PMID: 26064899. DOI: $10.1155 / 2015 / 341327$

6 Phillippi JA, Miller E, Weiss L, Huard J, Waggoner A and Campbell P: Microenvironments engineered by inkjet bioprinting spatially direct adult stem cells toward muscle- and bone-like subpopulations. Stem Cells 26(1): 127-134, 2008. PMID: 17901398. DOI: 10.1634/stemcells.2007-0520 
7 Tarafder S, Balla VK, Davies NM, Bandyopadhyay A and Bose S: Microwave-sintered 3d printed tricalcium phosphate scaffolds for bone tissue engineering. J Tissue Eng Regen Med 7(8): 631641, 2013. PMID: 22396130. DOI: 10.1002/term.555

8 Martino MM, Briquez PS, Maruyama K and Hubbell JA: Extracellular matrix-inspired growth factor delivery systems for bone regeneration. Adv Drug Deliv Rev 94(41-52), 2015. PMID: 25895621. DOI: 10.1016/j.addr.2015.04.007

9 Neveu V, Perez-Jimenez J, Vos F, Crespy V, du Chaffaut L, Mennen L, Knox C, Eisner R, Cruz J, Wishart D and Scalbert A: Phenol-explorer: An online comprehensive database on polyphenol contents in foods. Database (Oxford) 2010: bap024, 2010. PMID: 20428313. DOI: 10.1093/database/bap024

10 Weaver CM, Alekel DL, Ward WE and Ronis MJ: Flavonoid intake and bone health. J Nutr Gerontol Geriatr 31(3): 239-253, 2012. PMID: 22888840. DOI: 10.1080/21551197.2012.698220

11 Chen JR, Lazarenko OP, Shankar K, Blackburn ML, Badger TM and Ronis MJ: A role for ethanol-induced oxidative stress in controlling lineage commitment of mesenchymal stromal cells through inhibition of wnt/beta-catenin signaling. J Bone Miner Res 25(5): 1117-1127, 2010. PMID: 20200986. DOI: 10.1002/ jbmr.7

12 Chen JR, Lazarenko OP, Wu X, Kang J, Blackburn ML, Shankar $\mathrm{K}$, Badger TM and Ronis MJ: Dietary-induced serum phenolic acids promote bone growth via $\mathrm{p} 38 \mathrm{mapk} / \mathrm{beta}$-catenin canonical wnt signaling. J Bone Miner Res 25(11): 2399-2411, 2010. PMID: 20499363. DOI: 10.1002/jbmr.137

$13 \mathrm{Bu} \mathrm{SY,} \mathrm{Hunt} \mathrm{TS} \mathrm{and} \mathrm{Smith} \mathrm{BJ:} \mathrm{Dried} \mathrm{plum} \mathrm{polyphenols}$ attenuate the detrimental effects of tnf-alpha on osteoblast function coincident with up-regulation of runx2, osterix and igfi. J Nutr Biochem 20(1): 35-44, 2009. PMID: 18495459. DOI: 10.1016/j.jnutbio.2007.11.012

14 Trzeciakiewicz A, Habauzit V, Mercier S, Lebecque P, Davicco MJ, Coxam V, Demigne C and Horcajada MN: Hesperetin stimulates differentiation of primary rat osteoblasts involving the bmp signalling pathway. J Nutr Biochem 21(5): 424-431, 2010. PMID: 19427185. DOI: 10.1016/j.jnutbio.2009.01.017

15 Byun MR, Sung MK, Kim AR, Lee CH, Jang EJ, Jeong MG, Noh M, Hwang ES and Hong JH: (-)-epicatechin gallate (ecg) stimulates osteoblast differentiation via runt-related transcription factor 2 (runx2) and transcriptional coactivator with pdz-binding motif (taz)-mediated transcriptional activation. J Biol Chem 289(14): 9926-9935, 2014. PMID: 24515112. DOI: 10.1074/ jbc.M113.522870

16 Santiago-Mora R, Casado-Diaz A, De Castro MD and QuesadaGomez JM: Oleuropein enhances osteoblastogenesis and inhibits adipogenesis: The effect on differentiation in stem cells derived from bone marrow. Osteoporos Int 22(2): 675-684, 2011. PMID: 20495905. DOI: $10.1007 / \mathrm{s} 00198-010-1270-\mathrm{x}$

17 Patisaul $\mathrm{HB}$ and Jefferson W: The pros and cons of phytoestrogens. Front Neuroendocrinol 31(4): 400-419, 2010. PMID: 20347861. DOI: 10.1016/j.yfrne.2010.03.003

18 Takahama U, Yamauchi R and Hirota S: Interactions of starch with a cyanidin-catechin pigment (vignacyanidin) isolated from vigna angularis bean. Food Chem 141(3): 2600-2605, 2013. PMID: 23871000. DOI: 10.1016/j.foodchem.2013.04.065

19 Takahama U, Yamauchi $\mathrm{R}$ and Hirota S: Isolation and characterization of a cyanidin-catechin pigment from adzuki bean (vigna angularis). Food Chem 141(1): 282-288, 2013. PMID: 23768359. DOI: 10.1016/j.foodchem.2013.02.113
20 Yoshida K, Nagai N, Ichikawa Y, Goto M, Kazuma K, Koga K, Hashimoto M, Iuchi S, Takaya Y and Kondo T: Structure of two purple pigments, catechinopyranocyanidins A and B from the seedcoat of the small red bean, Vigna angularis. Sci Rep 9(1): 16716, 2019. PMID: 31700107. DOI: 10.1038/s41598-019-53406-9

21 Thies RS, Bauduy M, Ashton BA, Kurtzberg L, Wozney JM and Rosen V: Recombinant human bone morphogenetic protein-2 induces osteoblastic differentiation in w-20-17 stromal cells. Endocrinology 130(3): 1318-1324, 1992. PMID: 1311236. DOI: 10.1210/endo.130.3.1311236

22 Kokabu S, Gamer L, Cox K, Lowery J, Tsuji K, Raz R, Economides A, Katagiri T and Rosen V: BMP3 suppresses osteoblast differentiation of bone marrow stromal cells via interaction with Acvr2b. Mol Endocrinol 26(1): 87-94, 2012. PMID: 22074949. DOI: 10.1210/me.2011-1168

23 Kokabu S, Nojima J, Kanomata K, Ohte S, Yoda T, Fukuda T and Katagiri TProtein phosphatase magnesium-dependent 1Amediated inhibition of BMP signaling is independent of Smad dephosphorylation. J Bone Miner Res 25(3): 653-660, 2010. PMID: 19594322. DOI: 10.1359/jbmr.090736

24 Washio A, Nakagawa A, Nishihara T, Maeda H and Kitamura C: Physicochemical properties of newly developed bioactive glass cement and its effects on various cells. J Biomed Mater Res B Appl Biomater 103(2): 373-380, 2015. PMID: 24895094. DOI: 10.1002/jbm.b.33209

25 Livak KJ and Schmittgen TD: Analysis of relative gene expression data using real-time quantitative PCR and the 2(Delta Delta C(T)) Method. Methods 25(4): 402-408, 2001. PMID: 11846609. DOI: 10.1006/meth.2001.1262

26 Kokabu S, Nguyen T, Ohte S, Sato T, Katagiri T, Yoda T and Rosen V: TLE3, transducing-like enhancer of split 3, suppresses osteoblast differentiation of bone marrow stromal cells. Biochem Biophys Res Commun 438(1): 205-210, 2013. PMID: 23880346. DOI: $10.1016 /$ j.bbrc.2013.07.054

27 Ogawa M, Yaginuma T, Nakatomi C, Nakajima T, TadaShigeyama Y, Addison WN, Urata M, Matsubara T, Watanabe K, Matsuo K, Sato T, Honda H, Hikiji H, Watanabe S and Kokabu S: Transducin-like enhancer of split 3 regulates proliferation of melanoma cells via histone deacetylase activity. Oncotarget 10(3): 404-414, 2019. PMID: 30719233. DOI: 10.18632/ oncotarget.26552

28 Yu DQ, Lv PP, Yan YS, Xu GX, Sadhukhan A, Dong S, Shen Y, Ren J, Zhang XY, Feng C, Huang YT, Tian S, Zhou Y, Cai YT, Ming ZH, Ding GL, Zhu H, Sheng JZ, Jin M and Huang HF: Intrauterine exposure to hyperglycemia retards the development of brown adipose tissue. FASEB J 33(4): 5425-5439, 2019. PMID: 30759346. DOI: 10.1096/fj.201801818R

29 Seto I, Asahina I, Oda M and Enomoto S: Reconstruction of the primate mandible with a combination graft of recombinant human bone morphogenetic protein-2 and bone marrow. J Oral Maxillofac Surg 59(1): 53-61; discussion 62-53, 2001. PMID: 11152190. DOI: $10.1053 /$ joms.2001.19286

30 Harvey N, Dennison E and Cooper C: Osteoporosis: impact on health and economics. Nat Rev Rheumatol 6(2): 99-105, 2010. PMID: 20125177. DOI: 10.1038/nrrheum.2009.260

Received December 1, 2020

Revised December 11, 2020

Accepted December 15, 2020 